\title{
Intravesical foreign body: clinical features and diagnostic clues
}

\author{
Amit Thatte, ${ }^{1}$ Simon Rajendran, ${ }^{1}$ Laura Murphy, ${ }^{2}$ Michael Allen ${ }^{3}$
}

${ }^{1}$ Department of Surgery, Royal College of Surgeons, Dublin, Ireland

${ }^{2}$ Department of Urology, Connolly Hospital, Dublin, Ireland

${ }^{3}$ Department of Surgery, Connolly Hospital, Dublin, reland

\section{Correspondence to}

Dr Simon Rajendran,

simonrajendran@gmail.com

Accepted 3 May 2014

\section{CrossMark}

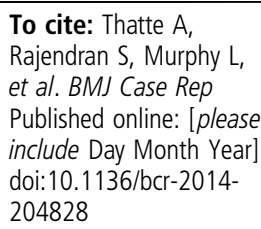

\section{DESCRIPTION}

A 32-year-old woman presented with lower abdominal pain. Her history included surgery for spina bifida, intermittent self-catheterisation and intravenous heroin use. Examination was unremarkable. Plain film abdomen revealed three calcified pelvic masses (figure 1). Given her history of heroin use, she was initially suspected of couriering illicit drugs through body packing. On retrospective review of images, masses on the anteroposterior image were not identified on the lateral image (figure 1) raising the suspicion of intravesical origin. On repeat questioning, the patient admitted to using various objects to assist with self-catheterisation. Ultrasound confirmed bladder calculi (figure 1) and cystolithotomy revealed intravesical foreign bodies (figure 2).

Intravesical masses may present diagnostic challenges in non-specialist clinical settings particularly when the history is unreliable. Common causes include iatrogenic (swabs, sutures) migrated intrauterine devices and direct self-insertion due to psychiatric illness and autoerotic stimulation. ${ }^{1}{ }^{2}$ Foreign objects induce inflammatory reactions and relative stasis within the bladder which allows precipitation and accumulation of calculi. In addition, patients with spina bifida have an increased risk of developing bladder stones. ${ }^{3}$ Ultrasound is the preferred imaging modality while CT scan is reserved in cases of negative ultrasound findings, when index of suspicion is high. ${ }^{2}$ Management include open or endoscopic cystolithotomy and intracorporeal or extracorporeal cystolithotripsy. ${ }^{2}$ Large and irregularly shaped objects make minimally invasive options less feasible. ${ }^{1}$ This case highlights the importance of identifying pertinent points in the history, determining high-risk patients for inserting foreign bodies and developing calculi with careful interpretation of imaging.

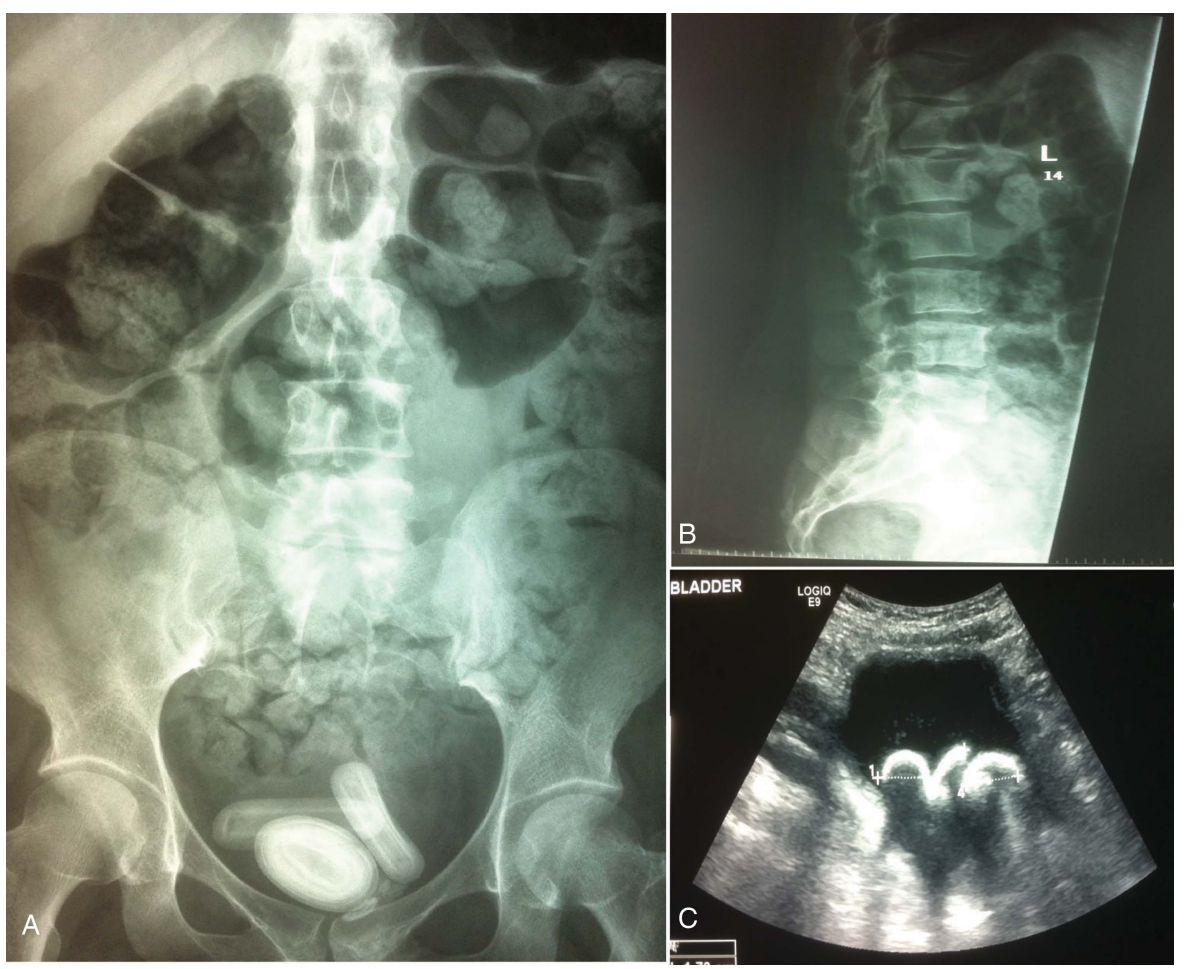

Figure 1 Preoperative imaging. (A) Anteroposterior plain film of the abdomen demonstrating three opacities in the pelvis. (B) Lateral plain film demonstrating absence of foreign body in the rectum. (C) Pelvic ultrasound revealing foreign bodies within the bladder. 

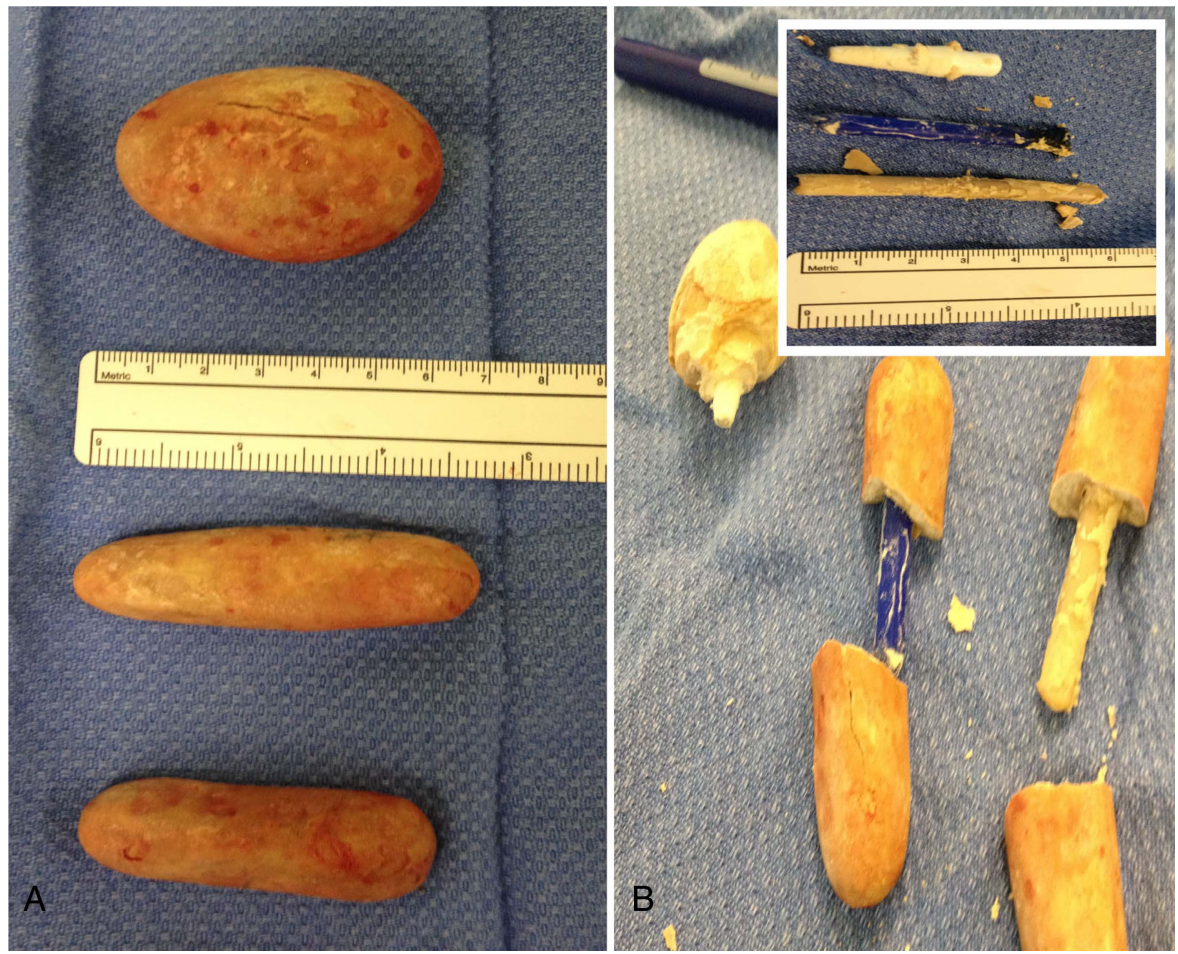

Figure 2 Open cystolithotomy findings. (A) Three large calculi and (B) contents of calculi displayed. (Inset: Contents of calculi were catheter tip, catheter segment and top of pen.)

\section{Learning points}

- Foreign bodies can present perplexing diagnostic challenges in the emergency department, particularly when the history is unreliable.

- A thorough history and careful interpretation of imaging provide important diagnostic clues for the further management of complex diagnostic cases.

- Ultrasound is the imaging modality of choice for intravesical foreign bodies while CT is reserved in cases of negative ultrasound findings, when index of suspicion is high.
Contributors All authors have contributed to the management of the patient and drafting of the manuscript. All authors have read and approved the final manuscript.

\section{Competing interests None.}

Patient consent Obtained.

Provenance and peer review Not commissioned; externally peer reviewed.

\section{REFERENCES}

1 Rafique M, Rauf A, Khan NA, et al. An unusual cause of vesical stone: a migrant intrauterine device. Eur J Contracept Reprod Health Care 2003;8:170-2.

2 Pirvu A, Ducos C, Sessa C, et al. Unusual foreign body in urinary bladder due to vascular surgery intervention. Urology 2013;81:e11-12.

3 Veenboer PW, Ruud Bosch JL, van Asbeck FW, et al. Urolithiasis in adult spina bifida patients: study in 260 patients and discussion of the literature. Int Urol Nephrol 2013;45:695-702

Copyright 2014 BMJ Publishing Group. All rights reserved. For permission to reuse any of this content visit

http://group.bmj.com/group/rights-licensing/permissions.

BMJ Case Report Fellows may re-use this article for personal use and teaching without any further permission.

Become a Fellow of BMJ Case Reports today and you can:

- Submit as many cases as you like

- Enjoy fast sympathetic peer review and rapid publication of accepted articles

- Access all the published articles

- Re-use any of the published material for personal use and teaching without further permission

For information on Institutional Fellowships contact consortiasales@bmjgroup.com

Visit casereports.bmj.com for more articles like this and to become a Fellow 